\title{
Ocular Injuries in Association with Middle Third Facial Injuries in Developing Countries: A Prospective Study
}

\author{
${ }^{1} \mathrm{~S}$ Mohanavalli, ${ }^{2} \mathrm{E}$ Suma, ${ }^{3} \mathrm{G}$ Senthamarai, ${ }^{4} \mathrm{G}$ Sree Vijayabala
}

\begin{abstract}
Introduction: The middle third of the face is the most common site of injury and is frequently complicated by associated ocular injuries. It may be simple laceration, ecchymosis, circumorbital edema, or severe as globe injury or injury to the optic nerve and vision loss. Even severe injury like internal bleeding causes increased intraocular pressure and damages the optic nerve; if managed earlier, it could prevent further damage and dysfunction of the eye. Midfacial fractures associated with ocular injuries should have an early ophthalmological examination to detect ocular injuries. Little is known about the current epidemiology of midface fractures and associated ocular injuries in Tamil $\mathrm{Nadu}$, the state of India. The aim was to study the etiology and pattern of middle third fracture and associated ocular injuries.
\end{abstract}

Materials and methods: This prospective study on midface fractures was carried out in the Department of Dentistry to analyze etiology, incidence, and patterns of midface fractures and associated ocular injuries. A total of 201 patients who reported with the history of midface injuries were included in the study. These patients were examined clinically and routine radiographs and computerized tomography magnetic resonance imaging (MRI) were taken to confirm the diagnosis. All the patients sustaining confirmed middle third fractures with or without eye signs were referred to an ophthalmology department for the evaluation and management of associated ophthalmic injury. Statistical Package for the Social Sciences software version 16.0 was used for data analysis. The outcome of the study was measured using percentages, mean, standard deviation, and test of proportion as appropriate.

Results: Traffic accident was the major cause of injury, mainly by motorized two wheelers (MTWs). Males in the 21 to 40 age group were common victims. Zygomatic complex fracture was the most common fracture type. Subconjunctival hemorrhage and infraorbital nerve injuries were common clinical findings.

Conclusion: Midthird facial injury cases should have an early ophthalmological examination for timely management to prevent dysfunction of the eye.

\footnotetext{
${ }^{1}$ Professor and Head, ${ }^{2,3}$ Associate Professor, ${ }^{4}$ Assistant Professor

${ }^{1,4}$ Department of Dentistry, ESIC Medical College and Postgraduate Institute of Medical Sciences and Research Chennai, Tamil Nadu, India

2,3 Department of Ophthalmology, ESIC Medical College and Postgraduate Institute of Medical Sciences and Research Chennai, Tamil Nadu, India

Corresponding Author: Mohanavalli S, Professor and Head, Department of Dentistry, ESIC Medical College and Postgraduate Institute of Medical Sciences and Research Chennai, Tamil Nadu, India, Phone: +91944106023, e-mail: mona13omfs@gmail.com
}

Keywords: Diplopia, Ecchymosis, Enophthalmos, Midface, Ocular.

How to cite this article: Mohanavalli S, Suma E, Senthamarai G, Vijayabala GS. Ocular Injuries in Association with Middle Third Facial Injuries in Developing Countries: A Prospective Study. World J Dent 2016;7(3):135-140.

\section{Source of support: Nil}

Conflicts of interest: None

\section{INTRODUCTION}

In developing countries, motorized two wheelers (MTWs) are the main mode of transport, and in India, its usage is nearly $70 \%$ more than in developed countries. Young adult males in the age group of 20 to 40 are the most common users of MTWs and are commonly involved in road traffic accidents (RTAs).$^{1-3}$ Road traffic accidents are the major cause of maxillofacial injuries. Maxillofacial injuries mainly involve the middle third of the face. Zygomatic complex fractures are among the common types of maxillofacial fracture and are frequently complicated by associated ocular injury. Orbital fractures are usually a part of the more complex midfacial trauma. ${ }^{4}$ Ocular complications may be laceration, ecchymosis, periorbital edema, or as severe as globe injury or injury to the optic nerve which results in vision loss. Severe injury may cause intraorbital bleeding which can lead to increased intraocular pressure and damages the optic nerve. If identified and managed earlier, it would prevent further damage and dysfunction of the eye. Early diagnosis of the ocular injury and appropriate management is essential to prevent morbidity. Some ocular injuries may require surgical treatment along with facial injuries, while in other circumstances the presence of an ocular injury would contraindicate immediate surgery to repair the facial fractures. All patients sustaining midfacial fractures associated with ocular injuries should have an early ophthalmological examination to decide about the nature of management. There is not much of published data regarding the current epidemiology of midface fractures and associated ocular injuries in Tamil Nadu state of Southern India. This prospective study was carried out to evaluate the etiology and pattern of middle third facial fractures, to evaluate the common types of ocular injuries in association with middle third fractures, and to study the major ocular complications in the middle third injuries. 


\section{MATERIALS AND METHODS}

A prospective study was carried out in the Department of Dentistry, ESIC Medical College and Postgraduate Institute of Medical Sciences and Research, K.K. Nagar, Chennai, from May 2014 to January 2016 to analyze the etiology, incidence, and patterns of midface fractures and associated ocular injuries. Statistical analysis using Statistical Package for the Social Sciences version 16.0 was done to report the results of the study. The outcome of the study was measured using percentages, mean, standard deviation, and test of proportion as appropriate. A total of 201 patients who reported with the history of midface injuries due to RTAs, assault, fall, sports injuries, and other causes were included in the study. These patients were examined clinically and routine radiographs like paranasal sinus view of the skull, submentovertex view/computerized tomography/ magnetic resonance imaging (MRI) were taken to confirm the diagnosis. All the patients sustaining confirmed middle third fractures with or without eye signs were referred to an ophthalmologist to rule out if any associated ophthalmic injury was present. In the Department of Ophthalmology, all patients were routinely evaluated as follows:

- A visual acuity test by Snellen's chart and color vision test with Ishihara pseudoisochromatic charts were performed. Intraocular pressure was assessed by noncontact tonometry.

- The position of globe: Examination from above with careful delineation of the position of the globe with respect to the supraorbital margin was carried out in all other patients.

- Enophthalmos and proptosis were measured by the anterior projection of eye measured relative to the outer edge of the orbit and assessed relative to the contralateral eye.

- Traumatic telecanthus was diagnosed by measuring the intercanthal and interpupillary distances. Telecanthus is said to be present when the intercanthal distance is increased, while the interpupillary distance is maintained in the normal range.

- Extraocular movement assessment and diplopia: Injury to extraocular muscles was ruled out by assessment of a range of eye movements in all directions of gaze and by diplopia charting. All motility abnormalities were quantified by means of prism cover test and forced duction testing performed when needed to rule out a nerve injury or muscle edema/contusion from a muscle entrapment.

- Periorbital edema and ecchymosis and subconjunctival hemorrhage were assessed clinically. Periorbital ecchymosis and dense subconjunctival hemorrhage with no posterior limit visible were followed up with an imaging to rule out basilar skull fractures.

- Slit-lamp examination was performed to rule out anterior segment injuries like corneoscleral tears, hyphema, iridodialysis, iris injury, uveitis, and lens injury.

- Posterior chamber injuries like retinal tears, retinal detachment, choroidal ruptures, macular edema, vitreous hemorrhage were confirmed by dilated slit-lamp examination with $90 \mathrm{D}$ lens, direct and indirect ophthalmoscopy.

- Pupillary assessment was performed. Traumatic optic neuropathy was ruled out in all cases.

When required, further investigations like CT/MRI, forced duction testing and management were done accordingly. Ophthalmic complications were managed by the Department of Ophthalmology as and when required.

Exclusion criteria included critically ill patients following severe injuries and not referred to our department, patients who sustained pure dental injuries (subluxation, luxation, and avulsion) and fractures of the alveolus process of the maxilla. Patients who had only soft tissue injuries of the facial region were also not included in this study.

\section{RESULTS}

Etiology and incidence (Table 1 and Graph 1): This study revealed that RTA was the major cause of injury

Table 1: Etiology for ocular injuries

\begin{tabular}{|c|c|c|c|c|c|c|c|c|c|c|c|c|c|c|}
\hline \multirow[b]{2}{*}{$\begin{array}{l}\text { Age } \\
\text { group }\end{array}$} & \multicolumn{3}{|c|}{ Gender distribution } & \multicolumn{4}{|c|}{ Etiology } & \multicolumn{7}{|c|}{ Pattern of midface fractures } \\
\hline & Male & Female & Total & RTA & Fall & Assault & Others & ZMC\# & $\begin{array}{l}\text { Lefort } \\
\text { I\# }\end{array}$ & $\begin{array}{l}\text { Lefort } \\
\text { II \# }\end{array}$ & $\begin{array}{l}\text { Lefort } \\
\text { III \# }\end{array}$ & $\begin{array}{l}\text { Orbital } \\
\text { bone/ } \\
\text { floor\# }\end{array}$ & $\begin{array}{l}\text { Nasal } \\
\text { bonel } \\
\text { floor \# }\end{array}$ & $\begin{array}{l}\text { Skull } \\
\text { bone }\end{array}$ \\
\hline $0-10$ & 0 & 2 & 2 & 1 & 1 & 0 & 1 & 1 & 0 & 0 & 0 & 1 & 0 & 0 \\
\hline $11-20$ & 6 & 0 & 6 & 4 & 1 & 0 & 1 & 5 & 0 & 0 & 1 & 1 & 0 & 0 \\
\hline $21-30$ & 60 & 9 & 69 & 61 & 7 & 1 & 0 & 41 & 1 & 29 & 4 & 5 & 3 & 4 \\
\hline $31-40$ & 38 & 23 & 61 & 50 & 5 & 5 & 1 & 39 & 2 & 13 & 7 & 8 & 6 & 0 \\
\hline $41-50$ & 29 & 8 & 37 & 25 & 2 & 8 & 2 & 20 & 3 & 13 & 3 & 4 & 4 & 2 \\
\hline $51-60$ & 15 & 6 & 21 & 13 & 8 & 0 & 0 & 17 & 1 & 3 & 3 & 4 & 3 & 1 \\
\hline $61-70$ & 1 & 4 & 5 & 2 & 3 & 0 & 0 & 3 & 0 & 1 & 0 & 0 & 0 & 0 \\
\hline Total & 149 & 52 & 201 & 156 & 26 & 14 & 5 & 126 & 6 & 56 & 24 & 28 & 17 & 7 \\
\hline$\%$ & 74 & 25.8 & & 77 & 12.9 & 6.9 & 2.4 & 62 & 2.9 & 27 & 11.9 & 13.9 & 8.4 & 3.5 \\
\hline
\end{tabular}


and accounts for $77 \%$ (156) followed by fall 12.9\% (26), and assault $6.9 \%$ (14); other causes like sports injury or industrial accidents were only $2.4 \%$ (5). Among RTA cases, MTWs were the major $(76 \%, 120)$ cause of injury. Adult males in the age group of 21 to 40 years were commonly injured; $74.2 \%$ of victims were males and $24.8 \%$ were females (Graph 2 ).

Types of fracture (Graph 3): Zygomatic complex fracture was the most common type (62\%), followed by Lefort II which accounts for $27 \%$. Orbital bone fracture that includes floor, inferior orbital rim, a medial/lateral wall of orbit and superior orbital rim comprises 13.9\%, Lefort III was $11.9 \%$, nasal bone fractures were $8.4 \%$, and fractures involving other skull bone like temporal or bases of the skull were $3.5 \%$. The zygomatic complex fracture was found to be the common site of fracture among the midthird injuries.

Types of ocular injury (Table 2 and Graph 4): Periorbital edema/ecchymosis seen in $79 \%$ and subconjunctival hemorrhage seen in $76.11 \%$ were the common clinical findings associated with these fractures. Macular edema occurred

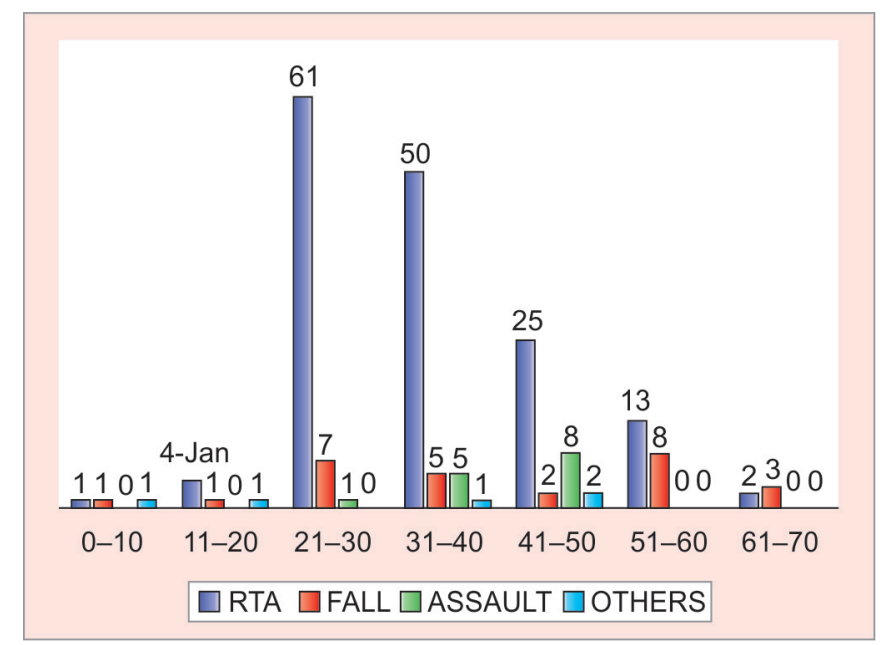

Graph 1: Etiology

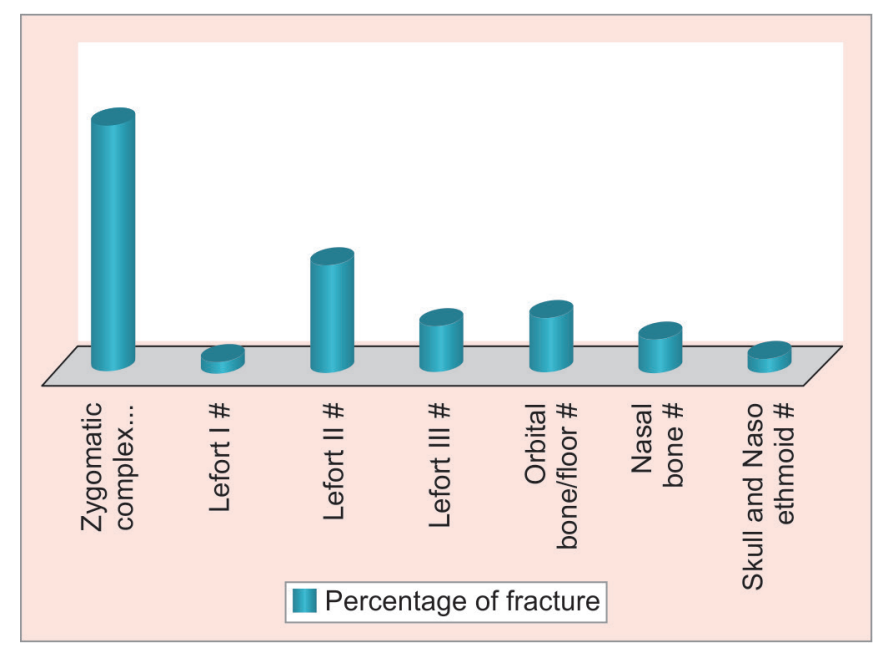

Graph 3: Pattern and percentage of middle third facial fractures in $16.93 \%$, reduced acuity in $13.93 \%$, anterior chamber injuries in $12.3 \%$, diplopia/limitation of extraocular movements in $11.5 \%$, enophthalmos in $10.94 \%$, telecanthus in $8.45 \%$ of the patients. Posterior chamber injuries accounted for only $6.9 \%$ of ocular involvement.

Nerve injury associated with midthird fractures was also recorded in this study. Mild to severe types of injuries were reported, in which the infraorbital nerve involvement was present in nearly $36.8 \%$ of cases, followed by optic nerve injury being noted in $5.4 \%$ of patients, a zygomatic branch of maxillary nerve involvement was seen in $5.4 \%$, and supraorbital nerve injury was also present in one patient with depressed front bone fracture.

\section{DISCUSSION}

In this prospective study, RTA was the major etiology of midthird injuries which accounts for nearly $77 \%$ of the cases. In India MTWs are the main means of transport, when compared with other developed countries. In this study, MTW was the major cause of injury in $76 \%$ of the total cases of RTA. These findings were consistent with

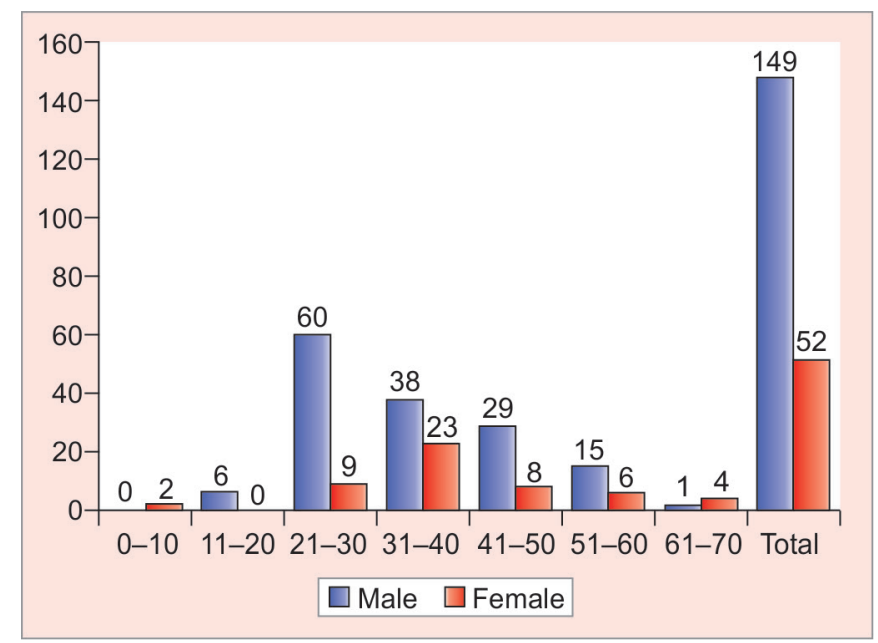

Graph 2: Gender distribution of midthird fractures

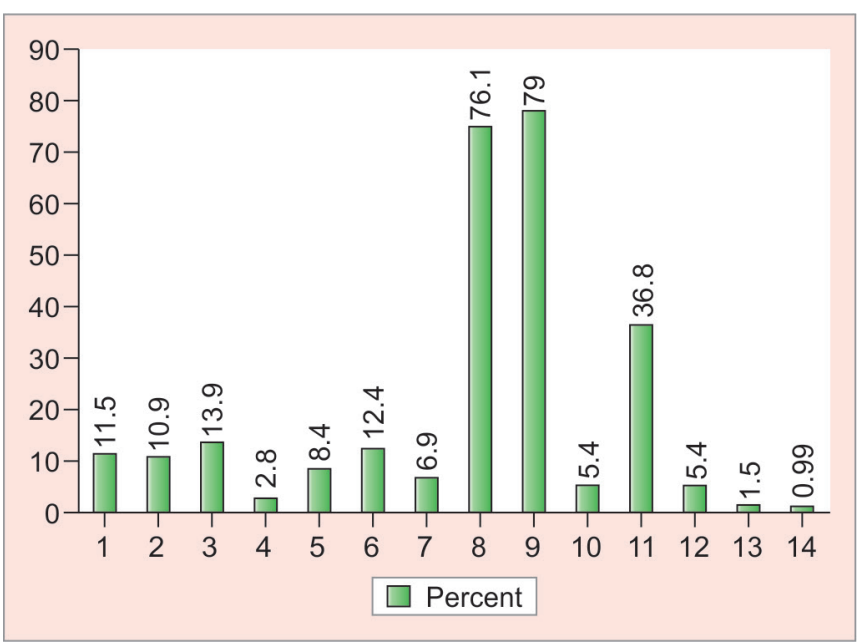

Graph 4: Types of ocular injuries 
Table 2: Types of ocular injuries

\begin{tabular}{rlll}
\hline SI. & no. of \\
no. & Type of ocular injury & $\begin{array}{l}\text { Percentage } \\
\text { patients } \\
(201)\end{array}$ & $\begin{array}{l}\text { of ocular } \\
\text { injury }\end{array}$ \\
\hline 1 & Diplopia & 28 & 11.5 \\
2 & Enophthalmos/EOM & 22 & 10.94 \\
& movement limitations & & \\
3 & Reduced acuity & 28 & 13.93 \\
4 & Macular edema & 34 & 16.9 \\
5 & Telecanthus & 17 & 8.45 \\
6 & Anterior chamber injury & 25 & 12.43 \\
7 & Posterior chamber injury & 14 & 6.96 \\
8 & Subconjunctival hemorrhage & 153 & 76.11 \\
9 & Periorbital edema/ecchymosis & 159 & 79 \\
10 & Optic nerve injury & 11 & 5.47 \\
11 & Infraorbital nerve injury & 74 & 36.8 \\
12 & Zygomatic facial branch of & 11 & 5.47 \\
& maxillary nerve injury & & \\
13 & Vision loss/globe injury & 3 & 1.5 \\
14 & Supra orbital nerve injury & 2 & 0.99 \\
\hline
\end{tabular}

findings from other studies. ${ }^{2-4}$ Other studies reported that adult males in the age group of 21 to 40 were commonly injured. In our series of cases, nearly $74.2 \%$ of victims were males and $25.8 \%$ were females. The mean age was 35.69 years ( (tandard deviation $=11.32$ ), the minimum age was 4 years and the maximum was 66 years. The male to female ratio was 2.99:1. This was slightly lower than that reported by Septa et al (3.16:1), Cheema, and others. ${ }^{1,3}$ This shows that females are more involved in social activities and frequently using MTW for the mode of transportation in our population. Previous studies have reported that the zygomatic complex fracture was the most common type in all facial middle third injuries. Our study showed that zygomatic complex fracture was $62 \%$. This is in comparison to Septa et $\mathrm{al}^{1}$ who showed $61 \%$ involvement of facial midthird fractures. These findings were consistent with findings from other countries. ${ }^{4}$ Midthird fractures are followed by Lefort II fractures amounting to $27 \%$ of injuries in our study; Septa et al ${ }^{1}$ reported $26.1 \%$ in their study. Lefort III was $11.9 \%$, the nasal bone fractures were $8.4 \%$, fractures involving other skull bone like temporal or bases of the skull were $3.5 \%$.

Ocular injuries vary from lacerations of the lids and abrasions of the cornea to wounds or ruptures of the sclera, intraocular hemorrhages, dislocation of the lens, and detachment of the retina. Ramneesh et $\mathrm{al}^{4}$ reported $18 \%$ patients had associated ocular injuries. Al-Qurainy et al, ${ }^{5,6}$ Ansari, ${ }^{7}$ and Wood $^{8}$ noted that zygomatic complex fractures had a significantly higher incidence of visual sequelae ( $41 \%)$ than other forms of midfacial injury.

In our study, periobital edema and ecchymosis (79\%) and subconjunctival hemorrhage $(76.11 \%)$ were the common clinical findings, present almost in all ocular injuries. This was followed by macular edema (16.93\%), reduced acuity (13.93), anterior chamber injuries (12.3\%), diplopia/limitation of extraocular muscle (EOM; $11.5 \%)$, and enophthalmos (10.94\%). Clauser et $\mathrm{al}^{9}$ defined enophthalmos as a backward, and usually downward, displacement of the globe into the bony orbit. In their study, patients with orbitozygomatic fractures and late posttraumatic patients were treated for enophthalmos. Septa reported $8.5 \%$ of enophthalmos in their cases and other studies reported 8 to $11 \%$ incidence. Our results are in accordance with other studies. ${ }^{1,5,7}$ Enophthalmos following facial trauma should raise the suspicion of an orbital wall fracture and a CT scan is advisable. Ramneesh et $\mathrm{al}^{4}$ reported that enophthalmos $(14 \%)$ was the most common complication in their study. Luo et $\mathrm{al}^{10}$ have emphasized on the need for early diagnosis and treatment. The goal is an anatomical reduction of fracture segments and restoration of the orbital volume as soon as possible. According to them, fracture reposition and orbital wall reconstruction should be performed early. Most of the zygomatic complex fractures and orbital floor fractures were treated by open reduction and fixation and for two patients orbital floor reconstruction was done with titanium orbital mesh.

Al-Qurainy et $\mathrm{al}^{5}$ reported that visual acuity was impaired in $15.4 \%$. Septa et al reported $11.5 \%$. We found that $13.93 \%$ (28) of patients had reduced visual acuity at the time of injury and out of this three patients had shown reduced acuity even after 3 months of follow-up.

Vision loss or blindness is an uncommon complication, it is reported between 0.3 and $3.5 \%$ by many authors. ${ }^{1,6,11,12}$ in their studies. Three of our patients $(1.5 \%)$ had permanent vision loss because of ruptured globe injury due to trauma. Vision loss is usually caused by direct injuries to the globe, and direct or indirect injury to the optic nerve or the visual pathway. ${ }^{13}$ In our study, 5.4\% (11) of patients had optic neuropathy, out of which $2.4 \%$ (5) had reduced visual acuity at the end of 3 months follow-up. Samardzic et $\mathrm{l}^{14}$ followed protocol suggested by Cerovski and reported $57.5 \%$ of patients on treatment with steroids showed visual improvement in their study. For optic neuropathy, Cerovski suggested that treatment should start preferably within the first 8 hours with megadoses of steroids for otherwise healthy individuals, because all patients were usually scared and psychologically traumatized and expect some sort of treatment when the vision loss is severe.

Hyphema or bleeding in the anterior chamber is mostly caused due to tearing of blood vessels at the root of the iris. ${ }^{1,11,15}$ In this study, hyphema/anterior chamber injury was present in $12.3 \%$, which is slightly higher than in other studies.

Traumatic telecanthus was present in $8.54 \%$ in our series, this is due to disruption of medial canthal ligament 
in Lefort III fractures or nasoethmoid complex fractures. Open reduction and direction fixation/close reduction for nasal bone fracture was done to correct the telecanthus. Mild deformity may persist even after a reduction in $4 \%$ of cases, because of commutated nasoethmoid complex fracture. Posterior chamber injuries $(3.48 \%)$ were treated by an ophthalmologist.

Neurosensory deficiency ranges from 18 to $56 \%{ }^{16-19}$ in all zygomatic complex and middle third fractures. The infraorbital nerve can also be damaged during fracture exposure/manipulation or plate/screw application. ${ }^{20}$ The nerve injuries reported in our study were mainly involvement of infraorbital nerve and optic nerve. The zygomatic branch of facial nerve, oculomotor, and supraorbital nerve were also involved in few cases because of trauma. In our study, nearly $36.8 \%$ cases of infraorbital nerve injury showed sensory loss, either parasthesia (altered sensation) or anesthesia (loss of sensation), especially in the displaced zygomatic complex fracture, due to traction or compression of the nerve. After decompression by elevation or open reduction and fixation of the fracture, the nerve function recovered within 3 to 6 months. Some of the undisplaced zygomatic complex fracture patients also reported numbness in the upper lip/upper teeth for 2 to 3 months and recovered thereafter. This may be due to compression of nerve by soft tissue hematoma in the cheek.

The zygomatic branch of maxillary nerve was involved in $5.4 \%$, mainly in depressed zygomatic arch fracture. These patients complained of numbness in the temporal region. Supraorbital nerve injury was present in one patient with a depressed fracture of the frontal bone.

The major ocular injuries reported in our series were subconjunctival hemorrhage and ecchymosis. It resolved after 4 to 6 weeks. Though the percentage was minimal, it was a great trauma to those patients. Nearly $56 \%$ male victims were under the influence of alcohol at the time of injury. Influence of alcohol was also a major cause of motorized vehicle accidents.

\section{MANAGEMENT}

Mostly, undisplaced zygomatic complex fractures can be managed conservatively, $45.8 \%$ patients were treated by conservative means only; $19.4 \%$ of patients with depressed zygomatic arch fracture were treated with closed reduction and $26 \%$ were treated by open reduction and internal fixation under general anesthesia.

Traumatic optic neuropathy was treated by immediate high dose of intravenous methylprednisolone followed by oral steroids. Corneoscleral tears were treated by suturing. Uveitis, hyphema, and macular edema were managed conservatively.

\section{CONCLUSION}

All orbital traumas need an ophthalmic evaluation preferably before any surgery is contemplated. Any injury in the eye or orbit if missed could adversely affect the visual function and prognosis, especially traumatic optic neuropathy, corneoscleral tears or hyphema; retinal injury may necessitate immediate management. Thus, the result of ophthalmic evaluation could influence the timing of the maxillofacial repair and also the outcome. Hence, a multidisciplinary approach will help the oral and maxillofacial surgeons to enhance the quality of treatment and reduce the associated ocular morbidity.

\section{REFERENCES}

1. Septa D, Newaskar VP, Agrawal D, Tibra S. Etiology, incidence and patterns of mid-face fractures and associated ocular injuries. J Maxillofac Oral Surg 2014 Apr-Jun;13(2): 115-119.

2. Gaddipati R, Ramisetti S, Vura N, Reddy KR, Nalamolu B. Analysis of 1,545 fractures of facial region - a retrospective study. Craniomaxillofac Trauma Reconstr 2015 Dec;8(4): 307-314

3. Cheema SA, Amin F. Incidence and causes of maxillofacial skeletal injuries at the Mayo Hospital in Lahore, Pakistan. Br J Oral Maxillofac Surg 2006 Jun;44(3):232-234.

4. Ramneesh G, Gulzar G, Sanjeev U, Rajinder M, Ranabir P, Nikhil G. A retrospective study of hundred patients of orbito zygomatic complex fracture with brain injury. J Clin Diagn Res 2014 Jul;8(7):NC04-NC06.

5. Al-Qurainy IA, Stassen LF, Dutton GN, Moos KF, el-Attar A. Diplopia following midfacial fractures. Br J Oral Maxillofac Surg 1991 Oct;29(5):302-307.

6. Al-Qurainy IA, Stassen LF, Dutton GN, Moos KF, el-Attar A. The characteristics of midfacial fractures and the association with ocular injury: a prospective study. Br J Oral Maxillofac Surg 1991 Oct;29(5):291-301.

7. Ansari MH. Blindness after facial fractures: a 19-year retrospective study. J Oral Maxillofac Surg 2005 Feb;63(2): 229-237.

8. Wood GD. Blindness following fracture of the zygomatic bone. Br J Oral Maxillofac Surg 1986 Feb;24(1):12-16.

9. Clauser L, Galiè M, Pagliaro F, Tieghi R. Posttraumatic enophthalmos: etiology, principles of reconstruction, and correction. J Craniofac Surg 2008 Mar;19(2):351-359.

10. Luo JC, Gui L, Zhang ZY, Teng L, Zhu JM, Hao TZ, Zhou Z. Early reconstruction of the periorbital injuries. Zhonghua Zheng Xing Wai Ke Za Zhi 2008 Sep;24(5):362-364.

11. Lim LH, Lam LK, Moore MH, Trott JA, David DJ. Associated injuries in facial fractures: review of 839 patients. Br J Plast Surg 1993 Dec;46(8):635-638.

12. Marín MI, Tejero TR, Dominguez FM, Gutiérrez ME. Ocular injuries in midfacial fractures. Orbit 1998 Mar;17(1): 41-46.

13. Ugboko VI, Udoye C, Olateju SO, Amole AO. Blindness and visual impairment from severe midface trauma in Nigerians. Int J Oral Maxillofac Surg 2006 Feb;35(2):127-131.

14. Samardzic K, Samardzic J, Janjetovic Z, Samardzic I, Sekelj S, Latic-Hodzic L. Traumatic optic neuropathy - to treat or to observe? J Acta Inform Med 2012 Jun;20(2):131-132. 
15. Barry C, Coyle M, Idrees Z, Dwyer MH, Kearns G. Ocular finding in patients with orbitozygomatic complex fractures: a retrospective study. J Oral Maxillofac Surg 2008 May; 66(5):888-892.

16. Benoliel R, Birenboim R, Regev E, Eliav E. Neurosensory changes in the infraorbital nerve following zygomatic fractures. Oral Surg Oral Med Oral Pathol Oral Radiol Endod 2005 Jun;99(6):657-665.

17. Afzelius LE, Rosén C. Facial fractures. A review of 368 cases. Int J Oral Surg 1980 Feb;9(1):25-30.
18. Bailey JS, Goldwasser MS, Ed Miloro M, Ghali GE, Larsen PE, Waite PD. Peterson's principles of oral and maxillofacial surgery. 2nd ed. Vol. 1. Hamilton: BC Decker Inc; 2004. p. 457.

19. Rowe NL, Williams JL. Row and William's maxillofacial injuries. 2nd ed. Vol. 1. Edinburgh: Churchill Livingstone; 1994. p. 512.

20. Kumar P, Godhi S, Lall AB, Ram CS. Evaluation of neurosensory changes in the infraorbital nerve following zygomatic fractures. J Maxillofac Oral Surg 2012 Oct-Dec;11(4): 394-399. 